\title{
Article \\ Arsenic Exposure, Arsenic Metabolism, and Glycemia: Results from a Clinical Population in New York City
}

\author{
Fen $\mathrm{Wu}^{1}$, Yu Chen ${ }^{1,2}$, Ana Navas-Acien ${ }^{3}{ }^{\circ}$, Michela L. Garabedian ${ }^{4}$, Jane Coates ${ }^{4}$ and Jonathan D. Newman ${ }^{4, *}$ \\ 1 Department of Population Health, New York University School of Medicine, New York, NY 10016, USA; \\ Fen.Wu@nyulangone.org (F.W.); Yu.Chen@nyulangone.org (Y.C.) \\ 2 Department of Environmental Medicine, New York University School of Medicine, New York, NY 10016, USA \\ 3 Department of Environmental Health Sciences, Columbia University Mailman School of Public Health, \\ New York, NY 10032, USA; an2737@cumc.columbia.edu \\ 4 Division of Cardiology and the Center for the Prevention of Cardiovascular Disease, Department of Medicine, \\ New York University School of Medicine, New York, NY 10016, USA; \\ Michela.Garabedian@nyulangone.org (M.L.G.); Jane.Coates@nyulangone.org (J.C.) \\ * Correspondence: Jonathan.Newman@nyulangone.org
}

check for updates

Citation: Wu, F.; Chen, Y.;

Navas-Acien, A.; Garabedian, M.L.; Coates, J.; Newman, J.D. Arsenic Exposure, Arsenic Metabolism, and Glycemia: Results from a Clinical Population in New York City. Int. J. Environ. Res. Public Health 2021, 18, 3749. https://doi.org/10.3390/ ijerph18073749

Academic Editor: Paul Tchounwou

Received: 12 March 2021

Accepted: 2 April 2021

Published: 3 April 2021

Publisher's Note: MDPI stays neutral with regard to jurisdictional claims in published maps and institutional affiliations.

Copyright: (C) 2021 by the authors. Licensee MDPI, Basel, Switzerland. This article is an open access article distributed under the terms and conditions of the Creative Commons Attribution (CC BY) license (https:/ / creativecommons.org/licenses/by/ $4.0 /)$.

\begin{abstract}
Little information is available regarding the glycemic effects of inorganic arsenic (iAs) exposure in urban populations. We evaluated the association of total arsenic and the relative proportions of arsenic metabolites in urine with glycemia as measured by glycated blood hemoglobin (HbA1c) among 45 participants with prediabetes ( $\mathrm{HbA} 1 \mathrm{c} \geq 5.7-6.4 \%)$, 65 with diabetes $(\mathrm{HbA} 1 \mathrm{c} \geq 6.5 \%)$, and 36 controls $(\mathrm{HbA} 1 \mathrm{c}<5.7 \%)$ recruited from an academic medical center in New York City. Each 10\% increase in the proportion of urinary dimethylarsinic acid (DMA\%) was associated with an odds ratio (OR) of 0.59 (95\% confidence interval (CI): 0.28-1.26) for prediabetes, $0.46(0.22-0.94)$ for diabetes, and $0.51(0.26-0.99)$ for prediabetes and diabetes combined. Each $10 \%$ increase in the proportion of urinary monomethylarsonic acid (MMA\%) was associated with a $1.13 \%(0.39,1.88)$ increase in HbA1c. In contrast, each $10 \%$ increase in DMA \% was associated with a $0.76 \%(0.24,1.29)$ decrease in HbA1c. There was no evidence of an association of total urinary arsenic with prediabetes, diabetes, or $\mathrm{HbA} 1 \mathrm{c}$. These data suggest that a lower arsenic methylation capacity indicated by higher MMA $\%$ and lower DMA \% in urine is associated with worse glycemic control and diabetes. Prospective, longitudinal studies are needed to evaluate the glycemic effects of low-level iAs exposure in urban populations.
\end{abstract}

Keywords: urinary arsenic; metabolites; type 2 diabetes; prediabetes; HbA1c; clinics

\section{Introduction}

The population of patients with dysglycemia including prediabetes (defined as an $\mathrm{HbA} 1 \mathrm{c}$ of $5.7 \%$ to $6.4 \%$ ) and type 2 diabetes (T2D) continues to grow [1]. There remains an unmet clinical need to identify potentially modifiable risk factors for dysglycemia. Exposure to inorganic arsenic (iAs) may be a novel target, as observational and experimental studies have found iAs to have adverse glycemic effects [2,3]. However, there are little to no data on the glycemic effects of iAs exposure in multi-ethnic, urban populations.

Exposure to iAs through drinking water and dietary sources (rice, grains and fruit juice) is common in the US [4-8]. Evidence from early studies in Taiwan and Bangladesh supports an association of high arsenic levels in drinking water $(\geq 150 \mu \mathrm{g} / \mathrm{L})$ with T2D [9-13], although most studies have been ecological [2]. At low-to-moderate levels of arsenic in drinking water $(<50 \mu \mathrm{g} / \mathrm{L})$, cross-sectional and prospective evidence from the United States, Mexico, and Denmark has shown mixed results regarding the possible role of iAs exposure in T2D [14-18]. Some studies that used total urinary arsenic levels as a biomarker of exposure reported no association between arsenic exposure and T2D or prediabetes [17,19,20], while others reported a positive dose-response relationship [3,18,21-26].

The toxicity of iAs is influenced by its metabolism [27]. After absorption, iAs is metabolized into monomethylarsonic acid (MMA) and dimethylarsinic acid (DMA), which 
are excreted in urine along with unmetabolized iAs. A reduced methylation capacity, characterized by a higher proportion of MMA (MMA\%) and lower proportion of DMA (DMA\%) in urine, has been identified as a risk factor for skin lesions, cardiovascular disease, and skin, lung, and bladder cancer [28-35]. In contrast, two studies reported that a higher methylation capacity, characterized by lower MMA\% and higher DMA \% in urine, was related to an increased risk of T2D $[18,20]$. Two other studies found no association between arsenic methylation capacity and dysglycemia [19,36]. No study has examined the association of urinary markers of iAs metabolism and dysglycemia in a multi-ethnic, urban population in a clinical setting; however, in this population, rates of diabetes and diabetic complications are among the highest in the United States [37]. An improved understanding of potential associations between urinary biomarkers of iAs exposure and dysglycemia in an urban population could further improve our understanding of the pathogenesis of diabetes and possibly uncover novel treatment or control pathways.

In the present study, we investigated the associations of total urinary arsenic concentration and urinary composition of arsenic metabolites with diabetes, prediabetes, and $\mathrm{HbA1c}$ in an urban clinical population.

\section{Methods}

\subsection{Study Population}

Patients were recruited as part of a protocol investigating the effects of iAs exposure on glycemic control and non-invasively measured vascular function. Study participants were identified by screening the electronic medical record (EMR) of outpatient visits in the offices of the NYU Faculty Group Practice and the New York Health and Hospital's Corporation Bellevue Hospital Adult Primary Care Clinic clinics. The EMR was reviewed for patients with normoglycemia, prediabetes (HbA1c $5.7-6.4 \%)$, or diabetes $(\mathrm{HbA} 1 \mathrm{c} \geq 6.5 \%)$ in the 6 months prior to enrollment; patients also met other study inclusion and exclusion criteria seen in outpatient practices. Other recruitment sources include ad-hoc referrals and the public posting of Institutional Review Board-approved flyers in the outpatient clinics. Full inclusion and exclusion criteria are listed in Supplemental Table S1. The study was conducted according to the guidelines of the Declaration of Helsinki, and approved by the Institutional Review Board of New York University School of Medicine (i15-00725; 30 July 2015). Informed consent was obtained from all subjects involved in the study. A total of 2411 patients were identified as eligible through EMR screening and pre-specified as control, pre-diabetic, or diabetic. From the pool of eligible patients, 967 were approached during their clinic appointment or contacted by phone by a member of the study team. Of these 967, reasons for non-participation or ineligibility are listed in Supplemental Table S2. Of the 967 patients contacted for potential enrollment, 423 scheduled a study appointment and data from 190 participants were collected (Supplemental Table S2). Of these, 62 patients had prediabetes, 84 patients had diabetes and 44 were patients without prediabetes or T2D. Study procedures, biospecimen collection and storage were reviewed with study participants who provided signed informed consent. A member of the research team also conducted a face-to-face interview and reviewed the clinical history, demographic information, and medication use of the individual.

\subsection{Clinical and Demographic Data}

$\mathrm{HbA1c}$ measurements used to categorize study participants were taken within six months prior to enrollment in the study. Parameters such as race, smoking status, current medications, and history of chronic kidney disease, heart attack, or stroke and other exclusion criteria were obtained from the EMR and confirmed during the interview. Body mass index (BMI), waist circumference, and family history of heart attack or stroke were obtained during the interview. 


\subsection{Arsenic Measurements}

Spot urine samples were collected in an arsenic and metal-free cryovial at recruitment and stored at $-80^{\circ} \mathrm{C}$. Total urinary arsenic was measured by inductively coupled plasma mass spectrometry (ICPMS) using a Perkin-Elmer NexION 350S ICP-MS (PerkinElmer, Waltham, MA, USA) at the Trace Metals Core Laboratory at Columbia University [38]. Urinary arsenic species (iAs, MMA, DMA, and the combination of arsenobetaine and arsenocholine (AsBC)) were measured on a Perkin-Elmer high performance liquid chromatography (HPLC) Series 200 Pump and Series 200 Autosamplers coupled to a Perkin-Elmer ELAN DRC II ICPMS [38]. Details on the methodology, including analytical standards, reference materials, and quality assurance/quality control, were described previously [39]. The limit of detection (LOD) for all arsenic species was $0.1 \mu \mathrm{g} / \mathrm{L}$. The percentages of individuals with urinary concentrations below the LOD were $23.8 \%, 10.2 \%, 0 \%$, and $3.4 \%$ for iAs, MMA, DMA, and AsBC, respectively. These participants were assigned a level equal to the LOD divided by the square root of 2 [40]. Urinary creatinine levels were measured by an automated alkaline picrate reagent method.

Urinary concentrations of total arsenic and arsenic metabolites (iAs, MMA, DMA, and AsBC) were adjusted for urinary creatinine to account for variations in hydration status [41] and expressed as micrograms per gram of creatinine. AsBC is considered to be non-toxic and is present as a large proportion of total arsenic in seafood [40]. Indicators of arsenic metabolism capacity were evaluated as the relative proportions of iAs, MMA, and DMA (iAs \%, MMA\%, and DMA\%) in urine, which were calculated by dividing each metabolite by the sum of iAs, MMA, and DMA [33]. To further remove the influence of AsBC, we also used the residual method to regress the measured total arsenic, iAs $\%, M M A \%$, and $\mathrm{DMA} \%$ on AsBC concentrations and extracted the residuals from the regression model. The residuals reflect total arsenic, iAs\%, MMA\%, and DMA \% not explained by AsBC [42,43].

\subsection{Statistical Analyses}

Of the 190 recruited participants, 146 and 139 participants, respectively, with complete data on total arsenic and species, creatinine, and AsBC were included in the final analysis of diabetes and $\mathrm{HbA1c}$. There were no significant differences in terms of demographic, lifestyle, and diabetes variables between included $(n=146)$ and non-included $(n=44)$ participants (data not shown). We conducted descriptive statistics for socio-demographic and As exposure variables, with the median and interquartile range for continuous variables and distribution (\%) for categorical variables, in the overall study population and by diabetes status (control, prediabetes, and diabetes). We used Chi-square and Kruskal-Wallis tests to detect group differences in categorical and continuous variables, respectively.

We used polytomous (generalized logit) logistic regression models to estimate odds ratios (ORs) for prediabetes and diabetes, using participants with a normal $\mathrm{HbA} 1 \mathrm{c}$ as the referent group, in relation to a $1 \mu \mathrm{g} / \mathrm{g}$ creatinine increase in urinary AsBC-adjusted total arsenic and a $10 \%$ increase in urinary AsBC-adjusted $\mathrm{iAs} \%, \mathrm{MMA} \%$, and $\mathrm{DMA} \%$. Since we were interested in understanding the glycemic effects of iAs exposure, we also combined participants a priori with abnormal glycemic control (prediabetes and diabetes) into one group and estimated ORs for this group relative to participants with normoglycemia. We first adjusted for sex and age (years) (model 1); then, we additionally adjusted for BMI (weight $(\mathrm{kg}) /$ height $\left(\mathrm{m}^{2}\right)$ ), smoking status (never vs. ever), and educational attainment (lower than high school vs. greater than high school) (model 2).

We used linear regression models to estimate the difference in $\mathrm{HbA} 1 \mathrm{c}$ associated with a $1 \mu \mathrm{g} / \mathrm{g}$ creatinine increase in urinary AsBC-adjusted total arsenic and a 10\% increase in urinary AsBC-adjusted iAs\%, MMA\%, and DMA\%, with the adjustment for covariates in model 1 and model 2 above. All analyses were performed using SAS (version 9.4, SAS Institute Inc., Cary, NC, USA). 


\section{Results}

Table 1 presents the characteristics of the study population overall and by diabetes status. Overall, approximately $40 \%$ of study participants were male and $51 \%$ were Hispanic, with a mean age of 56 years and a mean BMI of $30.5 \mathrm{~kg} / \mathrm{m}^{2}$. Prior smoking was common $(40 \%)$, and more than half $(53 \%)$ had an education level greater than high school. Participants with prediabetes were significantly younger than control participants and those with diabetes (Table 1). Control patients had a higher educational level than participants with abnormal glycemic control (prediabetes or diabetes). Urinary AsBC concentrations were lower in participants with prediabetes and diabetes than in controls, reflecting lower seafood intake in participants with dysglycemia relative to controls. There were no significant differences in measures of iAs exposure or metabolites by diabetes status.

Table 1. Distribution of population characteristics by diabetes status.

\begin{tabular}{|c|c|c|c|c|c|c|}
\hline Variable $^{a}$ & $\mathbf{N}$ & Overall $(n=190)$ & Controls $(n=44)$ & Prediabetes $(n=62)$ & Diabetes $(n=84)$ & $p$-Value ${ }^{b}$ \\
\hline Male & 190 & $72(37.9)$ & $16(36.4)$ & $27(43.6)$ & $29(34.5)$ & 0.69 \\
\hline Hispanic & 190 & $97(51.1)$ & $15(34.1)$ & $44(71.0)$ & $38(45.2)$ & 0.64 \\
\hline Age, years & 190 & $56(51-64)$ & $58(51.5-64)$ & $52.5(47-61)$ & $58(53-64)$ & 0.01 \\
\hline BMI, $\mathrm{kg} / \mathrm{m}^{2}$ & 187 & $30.5(27.0-34.1)$ & $29.1(26.0-32.0)$ & $30.4(26.1-34.5)$ & $31.0(28.3-34.3)$ & 0.07 \\
\hline Waist circumference, $\mathrm{cm}$ & 186 & $103.1(95.7-111.0)$ & $97.5(88.5-108.0)$ & $102.4(97.3-111.0)$ & $106.2(98.1-111.8)$ & 0.02 \\
\hline Ever smoked & 189 & $75(39.7)$ & $20(45.5)$ & $24(38.7)$ & $31(37.4)$ & 0.40 \\
\hline Greater than high school & 189 & $100(52.9)$ & $32(72.7)$ & $27(43.6)$ & $41(49.4)$ & 0.03 \\
\hline Urinary creatinine, $\mathrm{mg} / \mathrm{dl}$ & 178 & $106.8(60.4-171.3)$ & $97.5(46.0-156.1)$ & $132.1(64.7-187.6)$ & $102.2(60.7-179.0)$ & 0.19 \\
\hline Hemoglobin A1c, \% & 182 & $6.4(5.8-8.4)$ & $5.5(5.4-5.5)$ & $6.0(5.8-6.2)$ & $8.5(6.9-9.9)$ & $<0.0001$ \\
\hline Total arsenic, $\mu \mathrm{g} / \mathrm{L}$ & 150 & $13.3(6.6-27.7)$ & $13.4(6.4-35.7)$ & $15.5(8.1-34.0)$ & $12.1(6.6-23.6)$ & 0.78 \\
\hline iAs, $\mu \mathrm{g} / \mathrm{L}$ & 146 & $0.5(0.3-0.8)$ & $0.5(0.1-0.7)$ & $0.6(0.4-0.8)$ & $0.4(0.3-0.8)$ & 0.24 \\
\hline $\mathrm{MMA}, \mu \mathrm{g} / \mathrm{L}$ & 146 & $0.7(0.4-1.0)$ & $0.6(0.5-0.9)$ & $0.7(0.4-1.0)$ & $0.8(0.4-1.2)$ & 0.36 \\
\hline DMA, $\mu g / L$ & 146 & $6.0(3.1-10.8)$ & $6.0(2.8-11.1)$ & $5.8(3.6-10.7)$ & $6.1(3.1-9.8)$ & 0.97 \\
\hline $\mathrm{AsBC}, \mu \mathrm{g} / \mathrm{L}$ & 146 & $4.1(1.2-11.3)$ & $5.8(2.0-19.0)$ & $4.1(1.2-12.0)$ & $3.0(1.0-8.0)$ & 0.11 \\
\hline $\mathrm{iAs}+\mathrm{MMA}+\mathrm{DMA}, \mu \mathrm{g} / \mathrm{L}$ & 146 & $7.4(3.9-12.8)$ & $7.5(3.7-13.2)$ & $7.3(4.4-12.7)$ & $7.4(3.9-12.3)$ & 0.94 \\
\hline Total arsenic, $\mu \mathrm{g} / \mathrm{g}$ creatinine & 150 & $12.0(6.8-29.2)$ & $15.6(8.5-40.1)$ & $11.7(6.8-30.4)$ & $11.3(6.0-23.1)$ & 0.11 \\
\hline iAs, $\mu \mathrm{g} / \mathrm{g}$ creatinine & 146 & $0.4(0.2-0.7)$ & $0.4(0.2-0.6)$ & $0.5(0.3-0.7)$ & $0.4(0.2-0.7)$ & 0.59 \\
\hline MMA, $\mu \mathrm{g} / \mathrm{g}$ creatinine & 146 & $0.6(0.4-1.0)$ & $0.7(0.4-1.0)$ & $0.6(0.4-0.9)$ & $0.6(0.5-1.0)$ & 0.73 \\
\hline DMA, $\mu g / g$ creatinine & 146 & $5.2(3.3-9.0)$ & $6.6(4.0-12.3)$ & $4.9(3.3-8.1)$ & $4.5(3.1-9.0)$ & 0.32 \\
\hline AsBC, $\mu \mathrm{g} / \mathrm{g}$ creatinine & 146 & $4.2(1.2-11.9)$ & $7.5(3.6-25.4)$ & $3.8(1.0-9.5)$ & $2.7(1.1-7.5)$ & 0.01 \\
\hline $\begin{array}{c}\text { iAs + MMA + DMA, } \mu \mathrm{g} / \mathrm{g} \\
\text { creatinine }\end{array}$ & 146 & $6.7(4.1-10.7)$ & $7.7(4.7-13.4)$ & $6.0(3.9-9.4)$ & $5.5(4.0-11.1)$ & 0.33 \\
\hline $\mathrm{iAs} \%$ & 146 & $6.3(4.0-8.8)$ & $5.7(3.0-8.6)$ & $6.8(5.2-9.5)$ & $6.2(3.9-8.6)$ & 0.17 \\
\hline MMA\% & 146 & $10.4(6.3-13.2)$ & $8.2(5.9-13.7)$ & $10.4(7.2-11.8)$ & $10.9(6.6-13.2)$ & 0.50 \\
\hline DMA $\%$ & 146 & $83.7(78.4-88.1)$ & $86.3(78.8-90.5)$ & $83.3(78.4-86.1)$ & $82.1(78.4-88.1)$ & 0.26 \\
\hline
\end{tabular}

${ }^{a}$ Variables are shown as $n$ (\%) or median (interquartile range (IQR)) as appropriate. ${ }^{b} p$ values were computed with the Chi-square or Kruskal-Wallis test to detect group differences in categorical and continuous variables, respectively, among controls and respondents with prediabetes and diabetes. MMA: monomethylarsonic acid; DMA: dimethylarsinic acid; AsBC: the combination of arsenobetaine and arsenocholine.

There was a positive trend in the association of iAs\% with prediabetes and diabetes. Every $10 \%$ increase in $\mathrm{iAs} \%$ was associated with increased odds of prediabetes (OR: 2.89; 95\% CI: 0.67-12.5) and diabetes (OR: 3.42; 95\% CI: 0.86-13.6; Table 2). Every 10\% increase in MMA\% was also positively associated with prediabetes (OR: 1.67; 95\% CI: $0.54-5.19$ ) and diabetes (2.50; 95\% CI: 0.88-7.13). In contrast, each 10\% increase in DMA\% was associated with lower odds of prediabetes (OR: 0.59; 95\% CI: 0.28-1.26). Each 10\% increase in DMA\% was significantly associated with a $\sim 50 \%$ reduction in the odds of diabetes (OR: 0.46 ; 95\% CI: $0.22-0.94$ ) and dysglycemia (prediabetes and diabetes; OR: 0.51 ; 95\% CI: $0.26-0.99$ ). There was no evidence of an association of AsBC-adjusted total arsenic with prediabetes and diabetes. 
Table 2. Association (odds ratio (OR) ${ }^{a}$ (95\% confidence interval (CI)) between urinary arsenic and metabolism indices and diabetes.

\begin{tabular}{|c|c|c|c|}
\hline & $\begin{array}{l}\text { Prediabetes }(n=45) \text { vs. } \\
\text { Control }(n=36)\end{array}$ & $\begin{array}{l}\text { Diabetes }(n=65) \text { vs. } \\
\text { Control }(n=36)\end{array}$ & $\begin{array}{c}\text { Diabetes + Prediabetes } \\
(n=110) \text { vs. Control }(n=36)\end{array}$ \\
\hline \multicolumn{4}{|l|}{ Total arsenic $^{b}$} \\
\hline Model $1^{c}$ & $1.01(0.97-1.05)$ & $0.98(0.95-1.02)$ & $0.99(0.96-1.03)$ \\
\hline Model $2^{d}$ & $1.01(0.96-1.05)$ & $0.99(0.95-1.03)$ & $0.99(0.96-1.03)$ \\
\hline \multicolumn{4}{|l|}{$\mathrm{iAs} \%^{b}$} \\
\hline Model $1^{c}$ & $2.05(0.52-8.08)$ & $2.09(0.59-7.38)$ & $2.08(0.65-6.69)$ \\
\hline Model $2^{d}$ & $2.89(0.67-12.5)$ & $3.42(0.86-13.6)$ & $3.14(0.87-11.3)$ \\
\hline \multicolumn{4}{|l|}{$\mathrm{MMA}^{b}{ }^{b}$} \\
\hline Model $1^{c}$ & $1.53(0.52-4.50)$ & $2.21(0.85-5.76)$ & $1.96(0.81-4.79)$ \\
\hline Model $2^{d}$ & $1.67(0.54-5.19)$ & $2.50(0.88-7.13)$ & $2.19(0.83-5.76)$ \\
\hline \multicolumn{4}{|l|}{$\mathrm{DMA} \%{ }^{b}$} \\
\hline Model $1^{c}$ & $0.67(0.33-1.38)$ & $0.56(0.29-1.08)$ & $0.59(0.32-1.09)$ \\
\hline Model $2^{d}$ & $0.59(0.28-1.26)$ & $0.46(0.22-0.94)$ & $0.51(0.26-0.99)$ \\
\hline
\end{tabular}

${ }^{a}$ ORs for a $1 \mu \mathrm{g} / \mathrm{g}$ creatinine increase in total arsenic, and a $10 \%$ increase in urinary $\mathrm{iAs} \%, \mathrm{MMA} \%$, and DMA $\%{ }^{b}$ Adjusted for creatinine-adjusted arsenobetaine and arsenocholine using the residual method. ${ }^{c}$ Adjusted for sex and age (years). ${ }^{d}$ Adjusted for Model 1 variables plus body mass index, smoking status (never and ever), and educational attainment (lower than high school and greater than high school).

There was a positive association between urinary MMA\% and $\mathrm{HbA1c}$ (Table 3). For every $10 \%$ increase in MMA\%, there was a $1.13 \%(95 \%$ CI: $0.39,1.88)$ increase in $\mathrm{HbA} 1 \mathrm{c}$ (Model 2). DMA\% was inversely associated with $\mathrm{HbA1c}$, and every $10 \%$ increase in DMA\% was related to a $0.76 \%(95 \%$ CI: $0.24,1.29)$ decrease in $\mathrm{HbA} 1 \mathrm{c}$ (Model 2).

Table 3. Association $\left(\beta^{a}(95 \% \mathrm{CI})\right)$ between urinary arsenic and metabolism indices and serum hemoglobin A1c.

\begin{tabular}{cccc}
\hline Variable & $\boldsymbol{n}$ & Model 1 $^{\boldsymbol{b}}$ & Model 2 $^{\boldsymbol{c}}$ \\
\hline Total arsenicb $^{d}$ & 139 & $-0.01(-0.04,0.02)$ & $-0.01(-0.03,0.02)$ \\
iAs\% $^{d}$ & 139 & $0.60(-0.41,1.61)$ & $0.75(-0.28,1.78)$ \\
MMA $^{d}$ & 139 & $1.03(0.31-1.76)$ & $1.13(0.39-1.88)$ \\
DMA $^{d}$ & 139 & $-0.67(-1.19,-0.16)$ & $-0.76(-1.29,-0.24)$ \\
\hline
\end{tabular}

${ }^{a} \beta$ coefficients for a $1 \mu \mathrm{g} / \mathrm{g}$ creatinine increase in total arsenic, and a $10 \%$ increase in urinary $\mathrm{iAs} \%, \mathrm{MMA} \%$, and DMA \%. ${ }^{b}$ Adjusted for sex and age (years). ${ }^{c}$ Adjusted for Model 1 variables plus body mass index, smoking status (never and ever), and educational attainment (lower than high school and greater than high school). ${ }^{d}$ Adjusted for creatinine-adjusted arsenobetaine and arsenocholine using the residual method.

\section{Discussion}

In this case-control clinical study from a predominantly non-white, Hispanic population receiving medical care in a large, multi-institutional urban medical center, arsenic methylation capacity, but not total urinary arsenic, was associated with dysglycemia. A $10 \%$ increase in MMA\% was associated a $1.13 \%$ increase $\mathrm{HbA} 1 \mathrm{c}$, and a $10 \%$ increase in DMA $\%$ was associated a $0.76 \%$ decrease in $\mathrm{HbA} 1 \mathrm{c}$. We also observed an inverse association of urinary DMA\% with prediabetes and diabetes separately and combined. Additionally, we observed a non-significant trend towards increased odds of dysglycemia (prediabetes, diabetes or both) for each $10 \%$ increase in MMA\%.

Associations between urinary arsenic and diabetes or glycemia in populations with low-to-moderate iAs exposure have been inconsistent. Some cross-sectional studies have indicated that urinary arsenic was positively associated with prevalent diabetes or prediabetes in the US, Canada, and Spain $[3,22,25,44,45]$, while others have shown inconsistent associations between urinary arsenic and $\mathrm{HbA} 1 \mathrm{c}[3,17,25,44]$. In prospective cohort studies among the predominantly rural American Indian population, total urinary arsenic (median levels of 5.9, 21.1, and $10.2 \mu \mathrm{g} / \mathrm{L}$, respectively) was positively associated with diabetes in some $[24,36]$ but not all analyses [20].

Most prior studies assessing urinary arsenic in relation to diabetes or glycemia were conducted in non-urban populations, with drinking water as the main exposure source 
and low seafood consumption indicated by AsB (median ranging from 0.3-0.8 $\mu \mathrm{g} / \mathrm{L}$ ); median urinary arsenic ranged from 5.9-21.1 $\mu \mathrm{g} / \mathrm{L}$ in these studies $[3,20,24,36]$. Compared to these studies, our urban study population showed a similar level of urinary arsenic; the median urinary arsenic levels were 5.0 (IQR: 2.5-7.8) and 17.8 (IQR: 9.6-32.8) $\mu \mathrm{g} / \mathrm{L}$ among participants with low seafood consumption (AsBC $<1 \mu \mathrm{g} / \mathrm{L}$ ) [40] and those with higher seafood consumption (AsBC $\geq 1 \mu \mathrm{g} / \mathrm{L}$ ), respectively. Similar to some previous studies $[17,19,20]$, we did not find an association of total urinary arsenic with diabetes or prediabetes. We acknowledge that our sample sizes were limited in our analyses considering diabetes or prediabetes as a dichotomous outcome ( $\mathrm{HbA} 1 \mathrm{c} \geq 6.5 \%$ or $\geq 5.7-6.4 \%)$ as opposed to smaller effects of arsenic exposure on glycemic control.

Increasing evidence suggests an association between arsenic metabolism, dysglycemia, and diagnosed diabetes, although the nature of this association is not clearly understood $[18,20]$. Other studies have shown a positive relationship between lower arsenic methylation capacity (increased urinary MMA\% and lower DMA\%) and health outcomes including cancer and incident cardiovascular disease [30,31,33,35]. In contrast to prior studies $[18,20]$, we observed an association between lower methylation capacity (higher urinary MMA\% and lower DMA\%) and dysglycemia. Experimental evidence demonstrates that the majority of pancreatic As accumulation is in the form of MMA and DMA [46]. Some studies have shown that $24 \mathrm{~h}$ of exposure to subtoxic concentrations of toxic MMA ${ }^{\mathrm{III}}(1 \mu \mathrm{M})$ and DMA $\mathrm{DII}^{\mathrm{III}}(2 \mu \mathrm{M})$ could inhibit insulin-stimulated glucose uptake in cultured adipocytes [47] and decrease glucose-induced insulin secretion in isolated pancreatic islets $\left(0.1 \mu \mathrm{M}^{\mathrm{MMA}}{ }^{\mathrm{III}} / \mathrm{DMA}^{\mathrm{III}}\right)$ [48]. Another study demonstrated that $24 \mathrm{~h}$ of exposure to $\mathrm{MMA}^{\mathrm{III}}$ at both 0.375 and $0.5 \mu \mathrm{M}$ decreased glucose-stimulated insulin secretion in cultured pancreatic $\beta$ cells [49]. There was, however, no significant decrease observed upon $24 \mathrm{~h}$ of $\mathrm{DMA}^{\mathrm{III}}$ exposure, even at the highest dose $(2 \mu \mathrm{M})$ [49]. These data indicate the stronger detrimental effects of $\mathrm{MMA}^{\mathrm{III}}$ relative to DMA ${ }^{\mathrm{III}}$ on glucose homeostasis. Using urinary MMA $\%$ and DMA \% as indicators of methylation capacity and amounts of $\mathrm{MMA}^{\mathrm{III}}$ and DMA ${ }^{\mathrm{III}}$, our findings are consistent with these data. However, in epidemiologic studies, it is not possible to distinguish and quantify MMA ${ }^{\mathrm{III}}, \mathrm{MMA}^{\mathrm{V}}$, $\mathrm{DMA}^{\mathrm{III}}$, and $\mathrm{DMA}^{\mathrm{V}}$ separately in urine. $\mathrm{MMA}^{\mathrm{III}}$ and $\mathrm{DMA}^{\mathrm{III}}$ are very unstable in human urine and must be measured or stabilized immediately after collection, making these impractical for most human studies.

Our study is among the first to report an association of MMA\% and DMA\% with $\mathrm{HbA} 1 \mathrm{c}$ and diabetes in an urban population. Other strengths of this study include the objective assessment of prediabetes and diabetes based on blood $\mathrm{HbA} 1 \mathrm{c}$, the rigorous laboratory procedures and the low limit of detection of our assay for urinary arsenic and its metabolites [39], and standardized study protocols to determine relevant potential confounders. Our results should be interpreted cautiously given the case-control design of the study, which precludes us from determining temporality and thus limits any inferences about causality. We adjusted for several potential confounding factors, but the effect of unmeasured potential confounders such as other environmental/dietary factors or residual confounding remains a possibility. We also had a small number of controls, which may give our results limited statistical power. Urinary arsenic and its metabolites were measured in a single-spot urine sample, which cannot account for physiologic variation in urinary iAs metabolism and excretion. However, under chronic conditions of exposure, urine biomarkers for metals (e.g., As) can also serve as a proxy of long-term exposure [32,50,51]. In addition, $\mathrm{HbA} 1 \mathrm{c}$ was measured prior to collection of urine samples and may introduce non-differential measurement errors. However, HbA1c reflects average glycemia over approximately 3 months, and according to the guidelines of the endocrine society, the measurement of $\mathrm{HbA1c}$ should occur biannually during stable glycemic control [52], which was applicable to participants in this study. Therefore, we do not expect that $\mathrm{HbA} 1 \mathrm{c}$ fluctuated substantially between the measurement of A1c and collection of urine specimens for analysis. To account for urinary dilution, we adjusted for urinary creatinine levels, but this approach may be subject to reverse causality since diabetes is associated with 
renal impairment, which may affect creatinine excretion [2]. However, participants with abnormal renal function were excluded from our study.

\section{Conclusions}

Our results indicate that lower arsenic methylation, characterized by higher MMA\% and lower DMA\% in urine, was associated with dysglycemia. Prospective, longitudinal studies are needed to evaluate the impact of arsenic metabolism on glycemic control and diabetes, especially in populations with low levels of iAs exposure.

Supplementary Materials: The following are available online at https: / www.mdpi.com/article / 10.3390 /ijerph18073749/s1, Table S1: Inclusion and exclusion criteria, Table S2: Reasons for lack of participation or ineligibility.

Author Contributions: J.D.N. conceptualized and designed the study. M.L.G. and J.C. recruited the participants and collected data. F.W. carried out the analyses and drafted the manuscript. Y.C. and J.D.N. revised the manuscript. A.N.-A. critically reviewed the manuscript for important intellectual content. All authors have read and agreed to the published version of the manuscript.

Funding: This research was funded by the US National Heart, Lung, and Blood Institute grant number [5K23HL125991].

Institutional Review Board Statement: The study was conducted according to the guidelines of the Declaration of Helsinki, and approved by the Institutional Review Board of New York University School of Medicine (i15-00725; 30 July 2015).

Informed Consent Statement: Informed consent was obtained from all subjects involved in the study.

Data Availability Statement: The data presented in this study are available on request from the corresponding author. The data are not publicly available due to privacy.

Conflicts of Interest: The authors declare no conflict of interest.

\section{References}

1. Centers for Disease Control and Prevention. Estimates of Diabetes and Its Burden in the United States. National Diabetes Statistics Report. 2020. Available online: https://www.cdc.gov/diabetes/pdfs/data/statistics/national-diabetes-statistics-report.pdf (accessed on 28 August 2020).

2. Maull, E.A.; Ahsan, H.; Edwards, J.; Longnecker, M.P.; Navas-Acien, A.; Pi, J.; Silbergeld, E.K.; Styblo, M.; Tseng, C.H.; Thayer, K.A.; et al. Evaluation of the association between arsenic and diabetes: A National Toxicology Program workshop review. Environ. Health Perspect. 2012, 120, 1658-1670. [CrossRef] [PubMed]

3. Gribble, M.O.; Howard, B.V.; Umans, J.G.; Shara, N.M.; Francesconi, K.A.; Goessler, W.; Crainiceanu, C.M.; Silbergeld, E.K.; Guallar, E.; Navas-Acien, A. Arsenic exposure, diabetes prevalence, and diabetes control in the Strong Heart Study. Am. J. Epidemiol. 2012, 176, 865-874. [CrossRef]

4. Gilbert-Diamond, D.; Cottingham, K.L.; Gruber, J.F.; Punshon, T.; Sayarath, V.; Gandolfi, A.J.; Baker, E.R.; Jackson, B.P.; Folt, C.L.; Karagas, M.R. Rice consumption contributes to arsenic exposure in US women. Proc. Natl. Acad. Sci. USA 2011, 108, 20656-20660. [CrossRef] [PubMed]

5. Jackson, B.P.; Taylor, V.F.; Karagas, M.R.; Punshon, T.; Cottingham, K.L. Arsenic, organic foods, and brown rice syrup. Environ. Health Perspect. 2012, 120, 623-626. [CrossRef] [PubMed]

6. $\quad$ Kurzius-Spencer, M.; Burgess, J.L.; Harris, R.B.; Hartz, V.; Roberge, J.; Huang, S.; Hsu, C.H.; O’Rourke, M.K. Contribution of diet to aggregate arsenic exposures-an analysis across populations. J. Expo. Sci. Environ. Epidemiol. 2014, 24, 156-162. [CrossRef] [PubMed]

7. Carlin, D.J.; Naujokas, M.F.; Bradham, K.D.; Cowden, J.; Heacock, M.; Henry, H.F.; Lee, J.S.; Thomas, D.J.; Thompson, C.; Tokar, E.J.; et al. Arsenic and Environmental Health: State of the Science and Future Research Opportunities. Environ. Health Perspect. 2016, 124, 890-899. [CrossRef] [PubMed]

8. Cubadda, F.; Jackson, B.P.; Cottingham, K.L.; Van Horne, Y.O.; Kurzius-Spencer, M. Human exposure to dietary inorganic arsenic and other arsenic species: State of knowledge, gaps and uncertainties. Sci. Total. Environ. 2017, 579, 1228-1239. [CrossRef]

9. Lai, M.S.; Hsueh, Y.M.; Chen, C.J.; Shyu, M.P.; Chen, S.Y.; Kuo, T.L.; Wu, M.M.; Tai, T.Y. Ingested inorganic arsenic and prevalence of diabetes mellitus. Am. J. Epidemiol. 1994, 139, 484-492. [CrossRef]

10. Rahman, M.; Tondel, M.; Ahmad, S.A.; Axelson, O. Diabetes mellitus associated with arsenic exposure in Bangladesh. Am. J. Epidemiol. 1998, 148, 198-203. [CrossRef]

11. Rahman, M.; Tondel, M.; Chowdhury, I.A.; Axelson, O. Relations between exposure to arsenic, skin lesions, and glucosuria. Occup. Environ. Med. 1999, 56, 277-281. [CrossRef] 
12. Tseng, C.H.; Tai, T.Y.; Chong, C.K.; Tseng, C.P.; Lai, M.S.; Lin, B.J.; Chiou, H.Y.; Hsueh, Y.M.; Hsu, K.H.; Chen, C.J. Long-term arsenic exposure and incidence of non-insulin-dependent diabetes mellitus: A cohort study in arseniasis-hyperendemic villages in Taiwan. Environ. Health Perspect. 2000, 108, 847-851. [CrossRef]

13. Wang, S.L.; Chiou, J.M.; Chen, C.J.; Tseng, C.H.; Chou, W.L.; Wang, C.C.; Wu, T.N.; Chang, L.W. Prevalence of non-insulindependent diabetes mellitus and related vascular diseases in southwestern arseniasis-endemic and nonendemic areas in Taiwan. Environ. Health Perspect. 2003, 111, 155-159. [CrossRef]

14. Brauner, E.V.; Nordsborg, R.B.; Andersen, Z.J.; Tjonneland, A.; Loft, S.; Raaschou-Nielsen, O. Long-term exposure to low-level arsenic in drinking water and diabetes incidence: A prospective study of the diet, cancer and health cohort. Environ. Health Perspect. 2014, 122, 1059-1065. [CrossRef] [PubMed]

15. James, K.A.; Marshall, J.A.; Hokanson, J.E.; Meliker, J.R.; Zerbe, G.O.; Byers, T.E. A case-cohort study examining lifetime exposure to inorganic arsenic in drinking water and diabetes mellitus. Environ. Res. 2013, 123, 33-38. [CrossRef] [PubMed]

16. Zierold, K.M.; Knobeloch, L.; Anderson, H. Prevalence of chronic diseases in adults exposed to arsenic-contaminated drinking water. Am. J. Public Health 2004, 94, 1936-1937. [CrossRef] [PubMed]

17. Lampron-Goulet, E.; Gagnon, F.; Langlois, M.F. Association between consumption of private well water contaminated by low levels of arsenic and dysglycemia in a rural region of Quebec, Canada. Environ. Res. 2017, 159, 232-238. [CrossRef] [PubMed]

18. Mendez, M.A.; Gonzalez-Horta, C.; Sanchez-Ramirez, B.; Ballinas-Casarrubias, L.; Ceron, R.H.; Morales, D.V.; Terrazas, F.A.; Ishida, M.C.; Gutierrez-Torres, D.S.; Saunders, R.J.; et al. Chronic Exposure to Arsenic and Markers of Cardiometabolic Risk: A Cross-Sectional Study in Chihuahua, Mexico. Environ. Health Perspect. 2016, 124, 104-111. [CrossRef]

19. Chen, Y.; Ahsan, H.; Slavkovich, V.; Peltier, G.L.; Gluskin, R.T.; Parvez, F.; Liu, X.; Graziano, J.H. No association between arsenic exposure from drinking water and diabetes mellitus: A cross-sectional study in Bangladesh. Environ. Health Perspect. 2010, 118, 1299-1305. [CrossRef] [PubMed]

20. Kuo, C.C.; Howard, B.V.; Umans, J.G.; Gribble, M.O.; Best, L.G.; Francesconi, K.A.; Goessler, W.; Lee, E.; Guallar, E.; Navas-Acien, A. Arsenic Exposure, Arsenic Metabolism, and Incident Diabetes in the Strong Heart Study. Diabetes Care 2015, 38, 620-627. [CrossRef]

21. Del Razo, L.M.; Garcia-Vargas, G.G.; Valenzuela, O.L.; Castellanos, E.H.; Sanchez-Pena, L.C.; Currier, J.M.; Drobna, Z.; Loomis, D.; Styblo, M. Exposure to arsenic in drinking water is associated with increased prevalence of diabetes: A cross-sectional study in the Zimapan and Lagunera regions in Mexico. Environ. Health 2011, 10, 73. [CrossRef]

22. Navas-Acien, A.; Silbergeld, E.K.; Pastor-Barriuso, R.; Guallar, E. Rejoinder: Arsenic exposure and prevalence of type 2 diabetes: Updated findings from the National Health Nutrition and Examination Survey, 2003-2006. Epidemiology 2009, 20, 816-820, discussion e811-812. [CrossRef] [PubMed]

23. Coronado-Gonzalez, J.A.; Del Razo, L.M.; Garcia-Vargas, G.; Sanmiguel-Salazar, F.; Escobedo-de la Pena, J. Inorganic arsenic exposure and type 2 diabetes mellitus in Mexico. Environ. Res. 2007, 104, 383-389. [CrossRef] [PubMed]

24. Kim, N.H.; Mason, C.C.; Nelson, R.G.; Afton, S.E.; Essader, A.S.; Medlin, J.E.; Levine, K.E.; Hoppin, J.A.; Lin, C.; Knowler, W.C.; et al. Arsenic exposure and incidence of type 2 diabetes in Southwestern American Indians. Am. J. Epidemiol. 2013, 177, 962-969. [CrossRef]

25. Navas-Acien, A.; Silbergeld, E.K.; Pastor-Barriuso, R.; Guallar, E. Arsenic exposure and prevalence of type 2 diabetes in US adults. JAMA 2008, 300, 814-822. [CrossRef]

26. Velmurugan, G.; Swaminathan, K.; Veerasekar, G.; Purnell, J.Q.; Mohanraj, S.; Dhivakar, M.; Avula, A.K.; Cherian, M.; Palaniswami, N.G.; Alexander, T.; et al. Metals in urine in relation to the prevalence of pre-diabetes, diabetes and atherosclerosis in rural India. Occup. Environ. Med. 2018, 75, 661-667. [CrossRef] [PubMed]

27. Drobna, Z.; Styblo, M.; Thomas, D.J. An Overview of Arsenic Metabolism and Toxicity. Curr. Protoc. Toxicol. 2009, 42, 4.31.1-4.31.6.

28. Chen, Y.C.; Su, H.J.; Guo, Y.L.; Hsueh, Y.M.; Smith, T.J.; Ryan, L.M.; Lee, M.S.; Christiani, D.C. Arsenic methylation and bladder cancer risk in Taiwan. Cancer Causes Control 2003, 14, 303-310. [CrossRef]

29. Pu, Y.S.; Yang, S.M.; Huang, Y.K.; Chung, C.J.; Huang, S.K.; Chiu, A.W.; Yang, M.H.; Chen, C.J.; Hsueh, Y.M. Urinary arsenic profile affects the risk of urothelial carcinoma even at low arsenic exposure. Toxicol. Appl. Pharmacol. 2007, 218, 99-106. [CrossRef]

30. Steinmaus, C.; Bates, M.N.; Yuan, Y.; Kalman, D.; Atallah, R.; Rey, O.A.; Biggs, M.L.; Hopenhayn, C.; Moore, L.E.; Hoang, B.K.; et al. Arsenic methylation and bladder cancer risk in case-control studies in Argentina and the United States. J. Occup. Environ. Med. 2006, 48, 478-488. [CrossRef]

31. Yu, R.C.; Hsu, K.H.; Chen, C.J.; Froines, J.R. Arsenic methylation capacity and skin cancer. Cancer Epidemiol. Biomark. Prev. 2000, 9 , 1259-1262.

32. Ahsan, H.; Chen, Y.; Kibriya, M.G.; Slavkovich, V.; Parvez, F.; Jasmine, F.; Gamble, M.V.; Graziano, J.H. Arsenic metabolism, genetic susceptibility, and risk of premalignant skin lesions in Bangladesh. Cancer Epidemiol. Biomark. Prev. 2007, 16, 1270-1278. [CrossRef]

33. Chen, Y.; Wu, F.; Liu, M.; Parvez, F.; Slavkovich, V.; Eunus, M.; Ahmed, A.; Argos, M.; Islam, T.; Rakibuz-Zaman, M.; et al. A prospective study of arsenic exposure, arsenic methylation capacity, and risk of cardiovascular disease in Bangladesh. Environ. Health Perspect. 2013, 121, 832-838. [CrossRef]

34. Chen, Y.; Wu, F.; Graziano, J.H.; Parvez, F.; Liu, M.; Paul, R.R.; Shaheen, I.; Sarwar, G.; Ahmed, A.; Islam, T.; et al. Arsenic exposure from drinking water, arsenic methylation capacity, and carotid intima-media thickness in Bangladesh. Am. J. Epidemiol. 2013, 178, 372-381. [CrossRef] 
35. Melak, D.; Ferreccio, C.; Kalman, D.; Parra, R.; Acevedo, J.; Perez, L.; Cortes, S.; Smith, A.H.; Yuan, Y.; Liaw, J.; et al. Arsenic methylation and lung and bladder cancer in a case-control study in northern Chile. Toxicol. Appl. Pharmacol. 2014, 274, $225-231$. [CrossRef] [PubMed]

36. Grau-Perez, M.; Kuo, C.C.; Gribble, M.O.; Balakrishnan, P.; Spratlen, M.J.; Vaidya, D.; Francesconi, K.A.; Goessler, W.; Guallar, E.; Silbergeld, E.K.; et al. Association of Low-Moderate Arsenic Exposure and Arsenic Metabolism with Incident Diabetes and Insulin Resistance in the Strong Heart Family Study. Environ. Health Perspect. 2017, 125, 127004. [CrossRef]

37. American Diabetes Association. Introduction: Standards of Medical Care in Diabetes-2021. Diabetes Care 2021, 44, S1-S2. [CrossRef] [PubMed]

38. Hosgood, H.D.; Slavkovich, V.; Hua, S.; Klugman, M.; Grau-Perez, M.; Thyagarajan, B.; Graziano, J.; Cai, J.; Shaw, P.A.; Kaplan, R.; et al. Urinary Arsenic Species are Detectable in Urban Underserved Hispanic/Latino Populations: A Pilot Study from the Study of Latinos: Nutrition \& Physical Activity Assessment Study (SOLNAS). Int. J. Environ. Res. Public Health 2020, $17,2247$.

39. Scheer, J.; Findenig, S.; Goessler, W.; Francesconi, K.A.; Howard, B.; Umans, J.G.; Pollak, J.; Tellez-Plaza, M.; Silbergeld, E.K.; Guallar, E.; et al. Arsenic species and selected metals in human urine: Validation of HPLC/ICPMS and ICPMS procedures for a long-term population-based epidemiological study. Anal. Methods 2012, 4, 406-413. [CrossRef] [PubMed]

40. Jones, M.R.; Tellez-Plaza, M.; Vaidya, D.; Grau, M.; Francesconi, K.A.; Goessler, W.; Guallar, E.; Post, W.S.; Kaufman, J.D.; Navas-Acien, A. Estimation of Inorganic Arsenic Exposure in Populations with Frequent Seafood Intake: Evidence From MESA and NHANES. Am. J. Epidemiol. 2016, 184, 590-602. [CrossRef]

41. Vahter, M.; Bjorkman, L.; Goessler, W. Concentrations of biomarkers in spot urine samples need adjustment for variation in dilution-Comment on: "Distribution of urinary selenium and arsenic among pregnant women exposed to arsenic in drinking water". Environ. Res. 2006, 104, 312-313, discussion 314.

42. Willett, W.; Stampfer, M.J. Total energy intake: Implications for epidemiologic analyses. Am. J. Epidemiol. 1986, 124, 17-27. [CrossRef] [PubMed]

43. Willett, W.C.; Howe, G.R.; Kushi, L.H. Adjustment for total energy intake in epidemiologic studies. Am. J. Clin. Nutr. 1997, 65, 1220S-1228S. [CrossRef]

44. Feseke, S.K.; St-Laurent, J.; Anassour-Sidi, E.; Ayotte, P.; Bouchard, M.; Levallois, P. Arsenic exposure and type 2 diabetes: Results from the 2007-2009 Canadian Health Measures Survey. Health Promot. Chronic Dis. Prev. Can. 2015, 35, 63-72. [CrossRef] [PubMed]

45. Grau-Perez, M.; Navas-Acien, A.; Galan-Chilet, I.; Briongos-Figuero, L.S.; Morchon-Simon, D.; Bermudez, J.D.; Crainiceanu, C.M.; de Marco, G.; Rentero-Garrido, P.; Garcia-Barrera, T.; et al. Arsenic exposure, diabetes-related genes and diabetes prevalence in a general population from Spain. Environ. Pollut. 2018, 235, 948-955. [CrossRef] [PubMed]

46. Carmean, C.M.; Seino, S. Braving the Element: Pancreatic beta-Cell Dysfunction and Adaptation in Response to Arsenic Exposure. Front. Endocrinol. 2019, 10, 344. [CrossRef] [PubMed]

47. Walton, F.S.; Harmon, A.W.; Paul, D.S.; Drobna, Z.; Patel, Y.M.; Styblo, M. Inhibition of insulin-dependent glucose uptake by trivalent arsenicals: Possible mechanism of arsenic-induced diabetes. Toxicol. Appl. Pharmacol. 2004, 198, 424-433. [CrossRef] [PubMed]

48. Douillet, C.; Currier, J.; Saunders, J.; Bodnar, W.M.; Matousek, T.; Styblo, M. Methylated trivalent arsenicals are potent inhibitors of glucose stimulated insulin secretion by murine pancreatic islets. Toxicol. Appl. Pharmacol. 2013, 267, 11-15. [CrossRef]

49. Dover, E.N.; Beck, R.; Huang, M.C.; Douillet, C.; Wang, Z.; Klett, E.L.; Styblo, M. Arsenite and methylarsonite inhibit mitochondrial metabolism and glucose-stimulated insulin secretion in INS-1 832/13 beta cells. Arch. Toxicol. 2018, 92, 693-704. [CrossRef]

50. Navas-Acien, A.; Umans, J.G.; Howard, B.V.; Goessler, W.; Francesconi, K.A.; Crainiceanu, C.M.; Silbergeld, E.K.; Guallar, E. Urine arsenic concentrations and species excretion patterns in American Indian communities over a 10-year period: The Strong Heart Study. Environ. Health Perspect 2009, 117, 1428-1433. [CrossRef]

51. Shiue, I.; Hristova, K. Higher urinary heavy metal, phthalate and arsenic concentrations accounted for 3-19\% of the population attributable risk for high blood pressure: US NHANE.S.; 2009-2012. Hypertens Res. 2014, 37, 1075-1081. [CrossRef]

52. American Diabetes Association. 6. Glycemic Targets: Standards of Medical Care in Diabetes-2021. Diabetes Care 2021, 44, S73-S84. [CrossRef] [PubMed] 